Eur. J. Clin. Chem. Clin. Biochem.

Vol. 29, 1991, pp. 223-235

(C) 1991 Walter de Gruyter \& Co. Berlin - New York

\title{
Reference Methods as a Basis for Accurate Measuring Systems ${ }^{1}$ )
}

\author{
By J. Büttner \\ Institut für Klinische Chemie I der Medizinischen Hochschule Hannover
}

(Received January 22, 1991)

Summary: Reference methods, as part of a reference system, are essential for improving the accuracy of routine methods. They can help to establish worldwide compatibility of clinical chemical measurements and they provide an objective basis for quality control measures. The subject of analytical errors is treated in detail, then the concept of reference methods is developed. This review emphasizes the fundamental metrological aspects of reference methods and reference measurement technology. An overview is given of the most important analytical principles used for reference methods in clinical chemistry. The particular problems of reference methods for the determination of the catalytic activity concentration of enzymes are outside the scope of this review.

\section{Introduction}

Due to the development of methods and technology in recent decades, clinical chemical investigations have become very much faster and simpler. The improvement of the analytical reliability has not kept up with this technological advance.

The main problem is the poor comparability of the results of different laboratories and the application of different methods. The cause is the inadequate accuracy of many analytical methods.

The introduction of automated analysis systems has tended to make the problem even greater. Although many of these apparatuses can make precise measurements, the accuracy of the results is still not satisfactory. The inadequate accuracy of modern analysis systems is due to the incorrect metrological structure of the measurement systems. For example, calibration with primary standards or certified reference materials is not possible with many instruments. In addition, most of the aforementioned automated analysis sys-

\footnotetext{
1) Based on a lecture given at the Symposium "Reference Methods in Clinical Chemistry - Objectives, Trends, Problems" of the Congress Biochemische Analytik 90, München, May 8, 1990
}

tems today are equivalent to a "black box", i. e. the user is denied any intervention and any control of the measurement procedure, in particular the separate stages.

For medical and economic reasons, it is absolutely essential to improve the accuracy of the methods and thus obtain better comparability of the results. The efforts which the national systems for quality assurance have been making for many years to improve the accuracy have had only a limited success. Many different methods for the same quantity exist side by side, and produce results which are hardly or not at all comparable. One solution of the problem is to construct a reference system from reference methods and reference materials, with which the accuracy of routine methods can be reliably determined. This concept goes back to the pioneering work of the U.S. National Bureau of Standards (NBS, now: National Institute for Standards and Technology (NIST), Gaithersburg MD) in the early seventies $(1-5)$. The concept was developed during the seventies (see for example the conference report of the Atlanta Conferences in 1973 (6) and 1978 (7)) by the NBS in cooperation with the International Federation of Clinical Chemistry (8) and institutions like the Center of Disease Control (Atlanta, Ga.), the Community Bureau 
of Reference (BCR) of the European Community and several professional societies (9). Various countries, such as the United States (10) and the Federal Republic of Germany have built up their own national reference systems (11). In the Federal Republic of Germany since 1988 the reference system has been the basis of the official system of quality assurance, which is binding for all physicians (12).

The goals of a reference system in clinical chemistry are the following:

1. to establish worldwide compatibility of clinical chemical measurements,

2. to enable the evaluation of performance of routine laboratories on an objective basis within systems for quality control and quality assurance,

3. to permit the evaluation of accuracy of analytical systems for routine use.

The term compatibility which is used in metrology ${ }^{2}$ ) means the correspondence between measuring methods (13). The analytical results of compatible methods have a similar error structure. Thus, for a particular quantity, compatible methods give closely agreeing results within estimatable error limits.

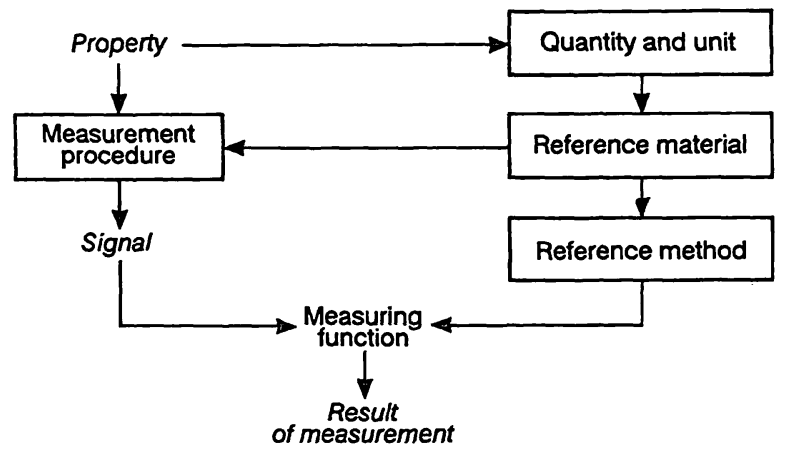

Fig. 1. The measuring system.

\section{Concept of the Metrologically Correct Measuring Sys- tem (14)}

The aim of a measurement is the quantitative determination of a property (fig. 1), in clinical chemical analysis for instance a property of the material being investigated, e. g. serum. For the measurement, firstly a suitable quantity expressing the property to be measured must be defined. By choosing a unit, the scale on which the measurement result is to be represented can be fixed. Finally, the measurement procedure converts the property to be measured to a signal which

2) Metrology is defined as the field of knowledge concerned with measurement (17)) furnishes the value either directly or by means of a calibration. The product of value and unit is the desired quantity.

It is crucially important for establishing objectively correct and thus universally comparable measurements that all measurements be converted to the International Unit System (Système International d'Unités (SI), for the use of SI units in Clinical Chemistry see 1.c. (15)). If the measurement procedure furnishes a base unit of the unit system directly this conversion presents no problem at all. Such measurements may be carried out as "absolute" measurements (16). However, in the case of many measurements, particularly in chemical analyses, direct conversion is not possible. In this case the signal measured is linked to the unit by an empirical calibration. For example, in a photometric concentration determination, the logarithmic signal ratio, the absorbance, must be related to the desired concentration of the substance amount.

This is done by the empirically determined analytical calibration function

$$
\mathrm{R}=f(\mathrm{q})
$$

where $\mathrm{R}=$ response (signal) and $\mathrm{q}=$ quantity to be measured, or by its inverse, the analytical measuring function

$$
\mathrm{q}=f(\mathrm{R})
$$

The calibration thus provides a "realization" or embodiment of the selected unit.

As regards the accuracy of the measurement carried out, the calibration is a particularly critical step of the entire measuring operation. In chemical analyses, reference materials embodying the analyte to be determined in an exactly defined form are necessary for correct calibration. A measurement procedure for a defined quantity and unit, calibrated with reference materials, will be referred to as metrologically correct.

\section{Measurement Error}

Extensive freedom from measurement errors is of decisive importance to the concept of a reference system. Therefore, before turning to the reference methods we shall introduce and explain the concept of errors in measurements (for a more detailed treatment of this subject see 1.c., o.c. $(18-21)$ ).

The assumption of an error in a measurement presumes that a "true value" exists for the quantity to be measured. This "true value", hiowever, fundamentally 


\section{The Roots of Modern Biochemistry}

\section{Fritz Lipmann's Squiggle and its Consequences}

Editors Horst Kleinkauf, Hans von Döhren, Lothar Jaenicke

1988. $17 \mathrm{~cm} \times 24 \mathrm{~cm}$. XII, 988 pages. Numerous illustrations.

Hardcover. DM 448,-; approx. US \$263.00 ISBN 3110115859

A Fritz Lipmann dedicatory volume, originating from the Memorial Meeting held in Berlin-Dahlem in 1987, presenting the major aspects of modern biochemistry and their development in 90 essays. The Warburg/Meyerhof era, the time of emigration and postwar science are revived. Contemporaries and coworkers together with other outstanding scientists describe the state of biochemistry in major fields: as it was, as it is now, and where it will be going. At the same time this volume is a reference book on Fritz Lipmann, the outstanding biochemist, and life scientist, who considered his concept of the energy-rich bond, symbolized by the squiggle, as his major achievement.

\section{From the Contents}

Fritz Lipmann 1899-1986 • Biochemistry Comes of Age ·

Molecular Biology Sharpens its Tools - Functional Dynamics:

The Squiggle-Symbol of Bioenergetics; Molecular Recognition and Communication - Evolution - List of Contributors - Lipmann's Coworkers at Massachusetts General Hospital, Boston, and the Rockefeller University, New York - Fritz Lipmann: Bibliography 1924-1985 - Author Index · Subject Index 


\title{
Proteases of Retroviruses
}

\author{
Proceedings of the Colloquium C 52 \\ 14th International Congress of Biochemistry \\ Prague, Czechoslovakia $\cdot$ July 10-15, 1988
}

\section{Editor Vladimir Kostka}

1989. $17 \mathrm{~cm} \times 24 \mathrm{~cm}$. XII, 206 pages. Numerous illustrations.

Hardcover. DM 198,-; approx. US \$ 100.00 ISBN 3110118203

The book "Proteases of Retroviruses" provides initial information in the rapidly developing field of examination of proteolytic enzymes involved in the life cycle of HIV and of the most important oncogenic retroviruses. It summarizes the advance of the knowledge of retroviral proteases achieved most recently in virology, molecular biology and enzymology. It will become and invaluable tool for researchers working in these fields as well as for those interested in the design of new antivirals.

\section{From the Contents}

Introduction - Characteristics of Viral Proteases - Retrovirus Gene Products and Their Processing - Biosynthesis and Biochemical Characteristics of Retroviral Proteases - Bacterial Expression, Processing and Characterization of Recombinant Retroviral Proteases - Mutational Analyses of Retroviral Proteases - Structure, Function and Evolution of Retroviral Proteases - Author Index · Abbreviations .

Subject Index 
cannot be exactly determined by a measurement. Dorsey has introduced (17) the concept "quaesitum" in order to avoid the problematical term "true value". The quaesitum of the investigation is the actual value of the quantity.

The "true value" can be set by definition, as has been done with the internationally agreed base units for measurement. For practical purposes an operational definition is helpful, as proposed by Uriano \& Cali (14): "The true value of a property is that value that can ultimately be traced to the base or derived units of measurement through experiments having no systematic errors (or with systematic error small relative to practical end-use requirement)".

For an error in measurements we can use an additive model (21) as explained in table 1. According to this model, various error components which may have positive or negative values are added onto the "true value" of the quantity to be measured. Of these components, a distinction may be made between the constant and variable ones. The important point is that some of these error components can be avoided by suitable experimental steps but that others are unavoidable. In analytical chemistry, to simplify matters a distinction is made usually only between systematic and random errors. It must however be pointed out that the systematic error can consist of both constant and variable components. In developing his quality control concept Shewhart drew attention to the fact that by accurate analysis of a measuring system the variable component of the error can to some extent be assigned to specific causes and thus possibly avoided (22). He referred to "assignable causes of error" (23). Examples are for instance the time-dependent variation of a quantity with temperature, air pressure or humidity. The time-dependent change in a reagent solution or the aging of a component of the measuring instrument may also cause such errors. By careful error analysis these errors may be detected and eliminated. There then remains the error which according to Shewhart is due to the "constant system of change causes". This system can be described in the following way: The probability $P$ that the value $x$ lies in the limits $(x+d x)$ and $(x-d x)$ is a function of $x$ and various unknown parameters $\lambda_{1}, \lambda_{2}, \ldots \lambda_{n}$

$$
\begin{aligned}
& \mathrm{P}((\mathrm{x}+\mathrm{dx})>\mathrm{x}>(\mathrm{x}-\mathrm{dx}))= \\
& \quad f\left(\mathrm{x}, \lambda_{1}, \lambda_{2}, \lambda_{3}, \ldots \lambda_{n}\right) .
\end{aligned}
$$

Shewhart calls this system "constant" because it is not dependent on time. This error will be referred to as "random error". It is usual to describe the random error as "imprecision" (24) by a suitable measure of dispersion (e.g. the standard deviation). Of course,
Tab. 1. Error model of analytical measurements.

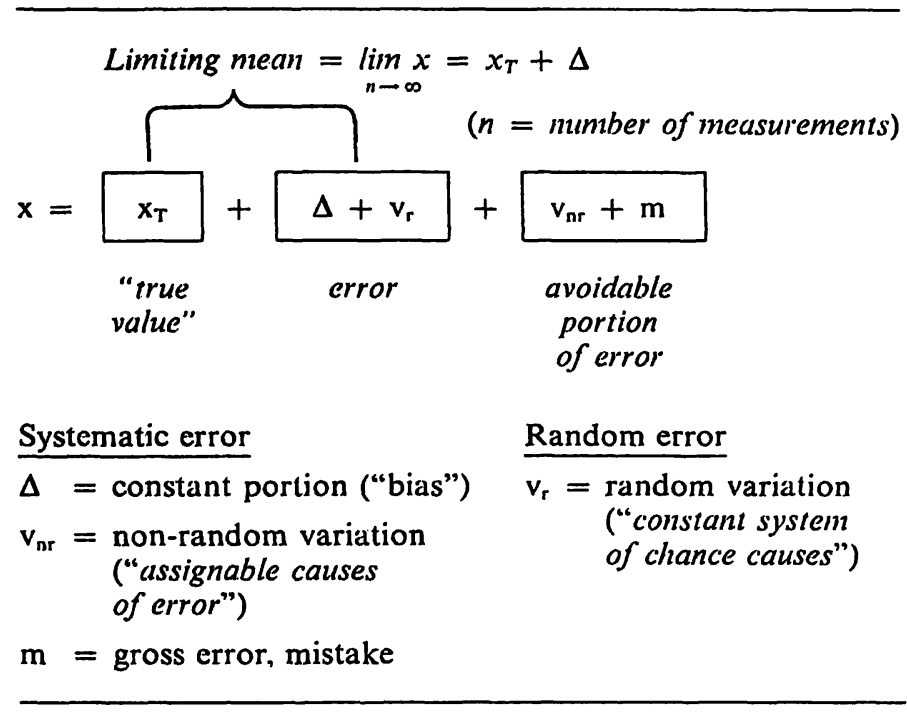

the "gross errors" which should not occur in an analysis carried out by an experienced analyst in accordance with an exact protocol can also be avoided.

Of particular significance to our problem is the constant portion of the error which is usually referred to as "systematic error" but for which to avoid ambiguity we shall choose the term "bias". The bias is a measure of the inaccuracy of a measurement. However, in the experimental determination of the bias, which will be discussed later, account must be taken of the random error. It is only after an infinitely large number of individual measurements that the so-called "limiting mean" (25) (see tab. 1) is reached, i. e. an expectation value for the quantity then only made up of the "true value" and the bias because the random error tends asymptotically to zero. Dorsey has defined the "limiting mean" in the following way (28):

"the mean of a family of measurements - of a number of measurements for a given quantity carried out by the same apparatus, procedure, and observer - approaches a definite value as the number of measurements is indefinitely increased. Otherwise, they could not properly called measurements of a given quantity".

Therefore the bias can be defined as the difference between the limiting mean and the true value (see tab. 1)

$$
\Delta=\lim _{n \rightarrow \infty} \mathrm{x}-\mathrm{x}_{\mathrm{T}}
$$

With a finite number of individual measurements, statistical methods must be employed to estimate the bias. In clinical chemistry, usually the bias is employed as a measure of the systematic errors without taking account of the imprecision, and it is referred to as 
"inaccuracy" (24). To conclude this brief consideration of errors, it is further pointed out that the error components referred to depend on various factors, for example the magnitude of the value and the matrix of the material investigated.

\section{Definitive Methods and Reference Methods}

When introducing the concept of a metrologically correct measuring system, we pointed out that for correct measurements the values must be traced back to the defined units of the unit system (SI). Exceptions are the methods, not unusual in medical investigations, whose results for various reasons are converted to arbitrarily defined units, e. g. methods in coagulation analysis. But even for quantities defined in SI units, it can be difficult to relate the analytical values directly to SI units if routine methods are used. Therefore exactly defined materials must be used for the calibration and these are referred to as reference materials (for the concept of reference materials see l.c., o.c. $(1,4,26))$. In these reference materials the quantity of interest is determined by methods of verifiably high accuracy. In this manner a routine method can be coupled with or related to the unit system.

It has been found expedient to carry out this process of establishing the relationship to the unit system step by step, using successively methods of different reliability. These methods are referred to as "reference methods" and "definitive methods" (24). This gives a hierarchy of methods $(14,24)$ (fig. 2) at the apex of which the experimental realization of the units of measurement themselves is found. As far as possible, definitive methods should be directly linked to the basic units of the International Unit System (SI). However, in chemical analysis such an "absolute" measurement is possible only in exceptional cases.

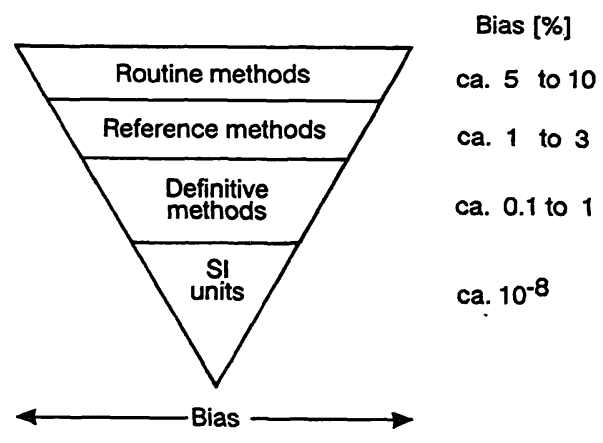

Fig. 2. The hierarchy of measurement methods (according to Uriano \& Cali (13)).

The term "definitive method" can be defined as follows: "A method which after exhaustive investigation is found to have no known source of inaccuracy or ambiguity" (24) (for a discussion of this definition see 1.c. $(7,27-30))$. The decisive factor in the suitability of a method as a definitive method is the absence of systematic errors.

The experimental expenditure and effort for definitive methods is great. As Cali said (5): " $A$ definitive method usually involves complex, costly, and highly sophisticated instrumentation manned by highly skilled and trained scientific specialists. The instruments and personnel for the development of definitive methods exist, literally, in only a small number of laboratories throughout the world".

For this reason these laboratories should be used primarily for the analysis of "Certified Reference $\mathrm{Ma}$ terial" (CRM).

For the analysis of materials for the calibration and control of routine methods, primarily "reference methods" are used, which involve less effort and expenditure than the definitive methods.

A definition of the reference method is given by the NBS: " $A$ reference method is an analytical method whose inaccuracy and imprecision are small enough, as demonstrated by direct comparison with the definitive method, and whose low incidence of susceptibility to known interferences is thoroughly documented that the stated end-purpose of the reference method may be achieved" (31) (another definition is given in an IFCC recommendation from 1978 (24)). The crucial point is the experimental proof that the inaccuracy of a reference method does not exceed certain error limits governed by the reference system.

\section{Analytical Principles for Reference Methods}

The definition of the concept "reference method" emphasizes the high accuracy and precision and the low susceptibility to disturbing interferences. It follows from this that when developing a reference method very careful consideration must be given to choice of the analytical principle which can be employed. In the case of many quantities, the great proneness to error of the routine methods usual in clinical chemistry make it necessary to choose for a reference method an analytical principle different from that employed in the routine method.

A systematic discussion of the reference methods available today would go beyond the scope of this review (see for example the review given by Uriano \& Gravatt (32)) and for this reason table 2 is intended to give a short overview of the most important analytical principles which are used for definitive or reference methods. In this overview we should observe 
Tab. 2. Analytical principles proposed for reference methods in clinical chemistry

\begin{tabular}{|c|c|}
\hline Method principle & Analyte \\
\hline ID-MS, ID-GC-MS & $\begin{array}{l}\text { Ca }(2,57), K(41,58) \text {, cholesterol }(59-64) \text {, glucose }(65-67) \text {, creatinine }(68,69) \text {, } \\
\text { urea }(70) \text {, uric acid }(71-73) \text {, glycerol }(74) \text {, oxalate }(75) \text {, steroids }(76-82,72) \text {, } \\
\text { thyroxine }(83,84) \text {, clomipramine }(85)\end{array}$ \\
\hline Potentiometry & $\mathrm{pH}(86,87)$ \\
\hline Coulometry & $\mathrm{Cl}(88)$ \\
\hline Flame cmission photometry & $\mathrm{K}(41), \mathrm{Na}(89,90)$ \\
\hline Atomic absorption spectrometry & $\mathrm{Ca}(2,91), \mathrm{Mg}(92), \mathrm{Li}(93), \mathrm{Ni}(94)$ \\
\hline Absorption photometry & $\begin{array}{l}\text { haemoglobin }(95,96) \text {, bilirubin }(97) \text {, cholesterol }(98,99) \text {, protein }(100) \text {, urea } \\
(101) \text {, uric acid }(102) \text {, glucose }(103,50)\end{array}$ \\
\hline Gas chromatography & cholesterol $(60,104)$, creatinine (105), antiepileptic drugs (106) \\
\hline High precision liquid chromatography & uric acid $(107,108,73)$, creatinine $(109)$, digoxine (110), oxalate (111) \\
\hline High precision ionic chromatography & inorganic phosphate (112) \\
\hline Isotachophoresis & $\mathrm{Na}(113)$ \\
\hline Ion exchange - gravimetry & $\mathrm{Na}(90)$ \\
\hline
\end{tabular}

that the principle of isotope dilution combined with mass spectrometry (ID-MS) has proved to be particularly suitable above all for the determination of organic substances. Recent reviews on this subject were given by de Leenheer et al. (33) and Siekmann (34). Particular problems arise for reference methods for the determination of the catalytic activity concentration of enzyme (35). A discussion of this point is outside the scope of this review.

\section{Metrological Aspects in the Development and Use of Reference Methods}

Reference methods differ from routine methods not only with regard to the analytical principles employed. Metrological aspects, with which we shall deal in somewhat more detail, are of central significance both in the development and in the execution of reference methods. Firstly, a few hints will be given for the metrologically correct structure of a reference method and then various problems encountered in the use of reference methods will be discussed.

The main aspect of a reference method is the careful investigation and monitoring of the errors. In particular, the inaccuracy should be kept as small as possible. This leads us to the question of how the bias, i. e. the systematic error, can be detected and quantified. The comparison, usual in the routine laboratory, of one method with another by parallel determinations and statistical evaluation of the data by means of simple regression analysis cannot be applied to the estimation of the bias. Apart from the fact that the bias of the comparison method is generally no more known than that of the method to be tested, the regression analysis (even when using structure relation models, e.g. principal component analysis (for a detailed description see Feldmann et al. (36)) furnishes only data on the random errors. For this reason the approach proposed by Carey et al. (37) comparing a method with a "battery of well-accepted methods" should not be used in a reference system which is designed according to metrological principles.

Two methods are available for determining the bias of reference methods, and as far as possible they should be used in combination:

1. the empirical method by analysis of reference materials,

2. the theoretical method of combining the errors of individual measurement steps.

The empirical method is obligatory for reference methods. It is essential to have suitable reference materials which as far as possible have been analysed with a definitive method, otherwise with another approved reference method. If no reference materials are available it cannot be proved that the accuracy of the method to be tested is adequate. John Mandel has put it in the following way: "The evaluation of accuracy in absence of reference value is an educated guess" (38). Reference materials can be analysed as such to determine the bias of the method to be tested, or they can be introduced into a biological matrix, for example in recovery experiments. Matrix-containing certified reference materials, such as the human serum SRM 909 of NIST, are also helpful.

The evaluation of the measurement results on reference materials, taking account of their dispersion, gives an estimate of the bias, for example a confidence interval which with the predefined probability includes the actual bias

$$
\left(x_{m}-x_{T}\right)-t \frac{s}{\sqrt{n}}<\Delta<\left(x_{m}-x_{T}\right)+t \frac{s}{\sqrt{n}}
$$

where $\Delta=$ bias, $x_{m}=$ mean, $x_{T}=$ "true value". $s$ 


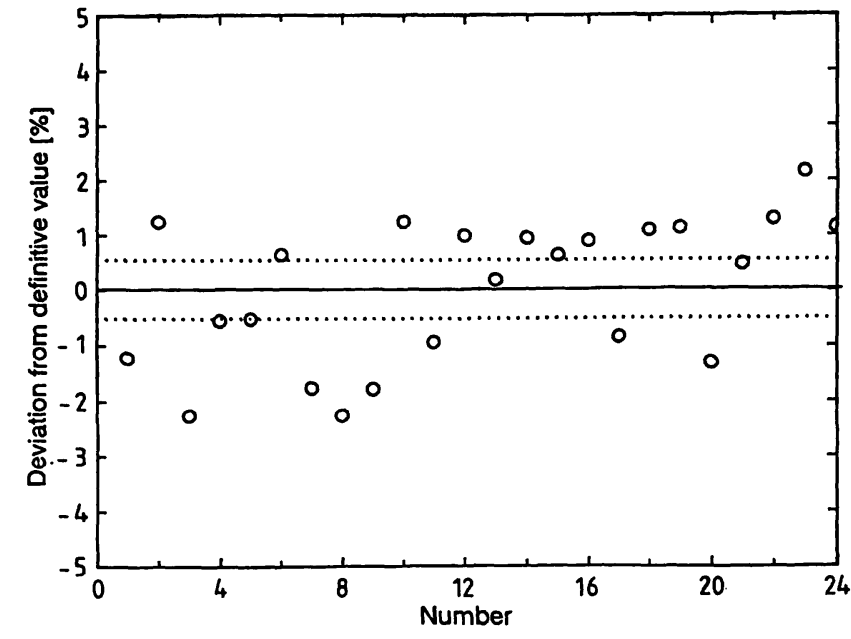

Fig. 3. Confidence interval of bias (Example: determination of glucose (SRM 909) using ID-MS reference method (67)). Hatched lines $=95 \%$ confidence interval; $\Delta=$ $0.023 ; s=1.301$.

$=$ standard deviation, $\mathrm{n}=$ number of measurements, and $\mathrm{t}=$ Student factor. An example is shown in figure 3.

The theoretical method for determining the bias is based on a careful analysis of the errors of the individual measurement steps. The bias may be deduced from these errors by application of the error propagation law' (39). Like most chemical analyses, reference methods are combinations of different measurements, for example of the mass, the volume or the light emission. The bias can be estimated for these individual measurements. This will be illustrated with the aid of a simple example (fig. 4). When using calibrated balances, pipettes and volumetric flasks for preparing standard solutions as employed in the calibration the bias of the weighed quantity, the volumetric solution or the dilution is known. From this, the bias of the standard solutions can be calculated. An upper limit of the bias ("maximum bias") can be determined on the basis of the general calibration error limits for official calibrated instruments given in the official weights and measures regulations (40).

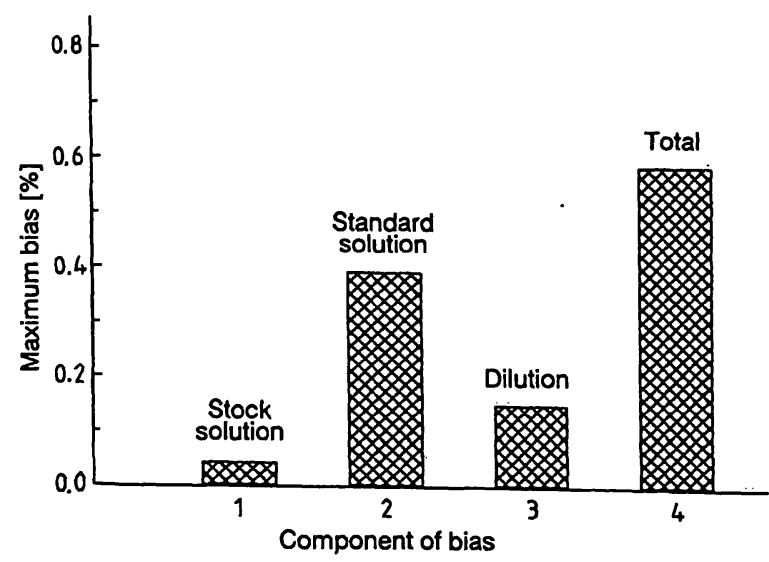

Fig. 4. Bias of calibration procedure (reference method potassium (NBS/NIST))
In most cases a chemical analysis method is a very complex process which is made up of a large number of individual measuring operations (e.g. specimen aliquotting and dilution, reagent(s) addition, time and temperature setting, calibration and the measuring of the signal which is generated by the transducer for the specimen and the blank). For more complex methods the bias of the overall procedure can only be estimated roughly by the theoretical method.

When developing a reference method, very particular care must be paid to designing the protocol of the method. The objective is to devise a test design which largely excludes possible sources of error. We have already pointed out, when discussing the general error model, that the part of the variable errors which can be assigned to specific causes can be avoided. As an example, the volumetric temperature error may be mentioned. The test design should ensure that variable errors are due exclusively to the unavoidable "constant system of chance causes". As an example, reference is made to the test design which has been developed on the basis of experience in the development of the classical reference procedure for potassium determination in serum by flame photometry (fig. 5) (41).
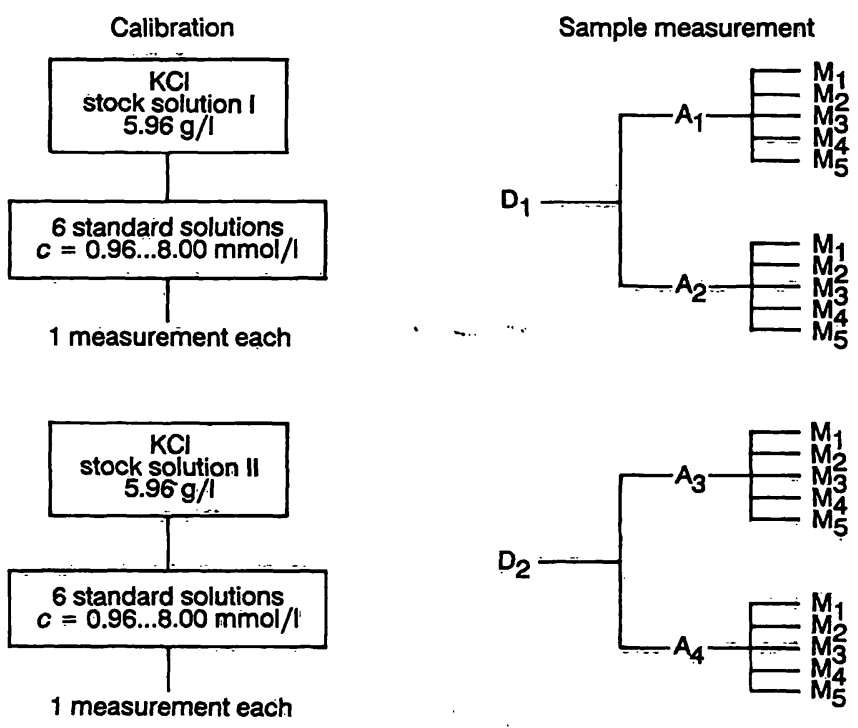

Fig. 5. Design of reference method for potassium (NBS/NIST) (41). $\mathrm{D}=$ day; $\mathrm{A}=$ Aliquot; $\mathrm{M}=$ measurement. $5.96 \mathrm{~g} / \mathrm{l}=80.0 \mathrm{mmol} / \mathrm{l} \mathrm{KCl}$

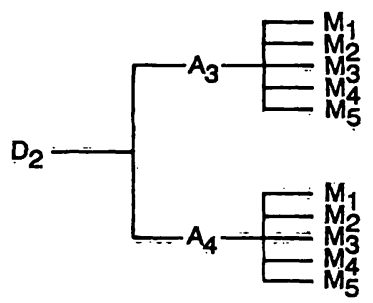

When developing a reference method, particular attention must be devoted to the calibration also. In reference methods it is absolutely essential to observe the basic analytical principle of calibration with primary, matrix-free standard solutions. Suitable reference material must be used for the calibration. $A$ reference method without reference material is not cor'rect metrologically. In the case of chemical analyses the reference material must consist of the respective 
analyte in ultrapure form, since otherwise no reference to the "true" substance amount is possible. To develop such reference materials, generally a definite method is unavoidable. Attention has already been drawn to the bias in the preparation of standard solutions. The stability of the standard solutions may also be critical.

In many physical and chemical methods, due to certain systematic errors nonlinear calibration functions are observed which result in a bias of a magnitude that is frequently difficult to estimate. This applies for example to methods like flame emission photometry and atomic absorption spectrometry and even to the isotope dilution-mass spectrometry method (due to the contribution of natural isotopes of the nonlabelled analyte to the recording of the labelled internal standard). To keep the bias as small as possible, a nonlinear calibration function as well the method of "bracketing" with linear interpolation is employed (2). This is illustrated in figure 6. Yap et al. (42) discussed the use of non-linear models for bracketing; for more complex mathematical methods see the paper by Schwartz (43).

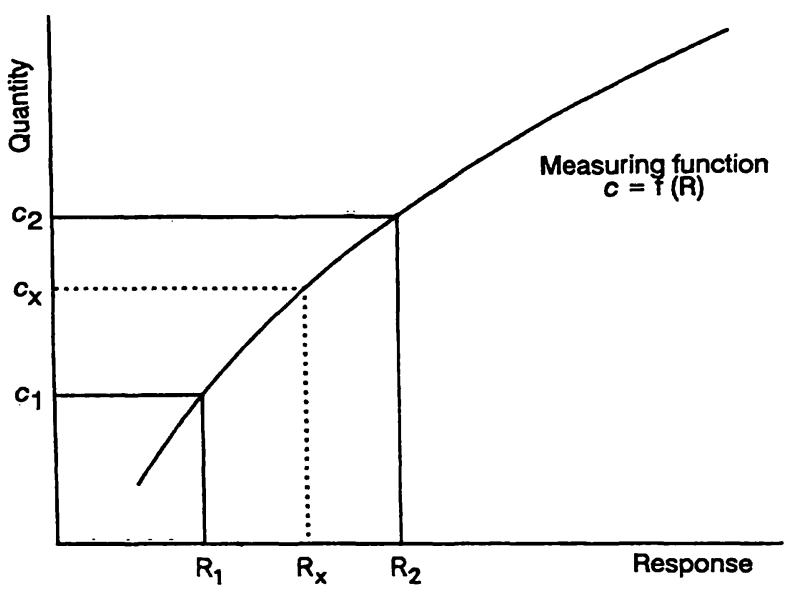

Fig. 6. Linear interpolation of measuring function.

$$
c_{\mathrm{x}}=c_{1}+\left(\mathrm{R}_{\mathrm{x}}-\overline{\mathrm{R}}_{1}\right) \cdot \frac{c_{2}-c_{1}}{\mathrm{R}_{2}-\mathrm{R}_{1}}
$$

In the development of a reference method for biological samples as investigated in clinical chemistry, particular attention must be paid to ensuring that the complex composition of the samples does not lead to errors due to interference or matrix effects. Serum, for example, is a complex microheterogeneous system containing hundreds of components. The detection and elimination of the errors resulting from this is in no way trivial and requires all the skill and experience of the analyst. One way to eliminate interferences by other components is to use high resolution separation procedures like gas chromatography combined with quantification of losses by isotope dilution as in the ID-GC-MS technique. The estimation of the error resulting from interferences is difficult. An error model can be developed if the sample to be analysed is considered as a multicomponent system with interactions between the components. A short illustration is given in table 3. Using the first terms of a Taylor series the general analytical calibration function can be approximated by a set of linear equations $(44,45)$. It is then possible to estimate the constant factors of these equations by multiple regression analysis of a set of experimental data. This model was used by Kroll et al. (46). A more general approach is the "Generalized standard addition method" proposed by Saxberg \& Kowalski $(47,48)$.

Tab. 3. General analytical calibration function with interferences.

\begin{tabular}{|c|c|c|c|}
\hline \multirow[t]{3}{*}{$\mathrm{R}=f_{0}\left(c_{0}\right)+$} & $f_{1}\left(c_{1}, c_{2}, c_{3} \ldots c_{n}\right)$ & + & $f_{2}\left(c_{0}, c_{1}, c_{2}, c_{3} \ldots c_{n}\right)$ \\
\hline & $\begin{array}{l}\text { Additive } \\
\text { interference term }\end{array}$ & & $\begin{array}{l}\text { Multiplicative } \\
\text { interference term }\end{array}$ \\
\hline & $\begin{array}{l}\text { Signal component } \\
\text { of interferent }\end{array}$ & & $\begin{array}{l}\text { Inhibition or } \\
\text { enhancement of } \\
\text { detection reaction }\end{array}$ \\
\hline \multirow[t]{2}{*}{ Examples } & $\begin{array}{l}\text { Optical } \\
\text { interference }\end{array}$ & & $\begin{array}{l}\text { Reagent consumption } \\
\text { by interferent }\end{array}$ \\
\hline & $\begin{array}{l}\text { Poor resolution } \\
\text { (chromatographic } \\
\text { separation) }\end{array}$ & & $\begin{array}{l}\text { Reaction } \\
\text { analyte-interferent }\end{array}$ \\
\hline
\end{tabular}

A decisive step in the development of a reference method is the transferability test. The method developed must also be executable in other laboratories with the same reliability as in the laboratory of the developer. The transferability is investigated in a study which is in principle designed in a manner similar to a interlaboratory test in quality control. Examples of well designed transferability tests are the studies on reference methods for calcium (49), glucose (50) and cholesterol (51). With such a study it can, for example, be recognized whether the protocol designed is detailed enough to avoid any additional error sources and whether the description of the individual steps is understandable and clear. The statistical evaluation of the data obtained (e.g. by analysis of variance) furnishes reliable information on the errors of the new method.

In contrast to a routine method, a reference method requires careful control also during the measurement procedure. This control should encompass two measures. Firstly, a procedure similar to the conventional 
Tab. 4. Performance criteria of measuring device.

Stability check of photometer

Example: Reference method for protein (CDC/NBS) (100)

Stability check of name photometer

Example: Reference method for potassium (NBS) (41)

Check AAS instrument

Example: Reference method for calcium (NBS/BCR) (2)
Absorbance of blank:

drift absorbance/h $\mathrm{h} \pm 0.002$

Repetition highest standard and blank deviation between results $\leqq 0: 04 \mathrm{mmol} / \mathrm{l}$ quality control to determine whether the measuring procedure is in order, i. e. whether it is reduced to the inevitable "constant system of chance causes" of Shewhart and whether variations not due to chance ("assignable causes of error" according to Shewhart) and, of course, gross errors are excluded. Secondly, the use of certain test criteria (performance criteria) in the individual sections of the measurement procedure; these criteria must be met before the next step is carried out (fig. 7). Some simple examples may be given to illustrate the foregoing. Before starting the actual measurement the satisfactory function of the measuring instrument used must be checked, i. e. freedom from drift, linearity of the display, temperature setting, etc. Some performance criteria of this type are enumerated in table 4. Absolutely essential in every measurement is the control of the calibration, because a main cause of systematic errors resides in

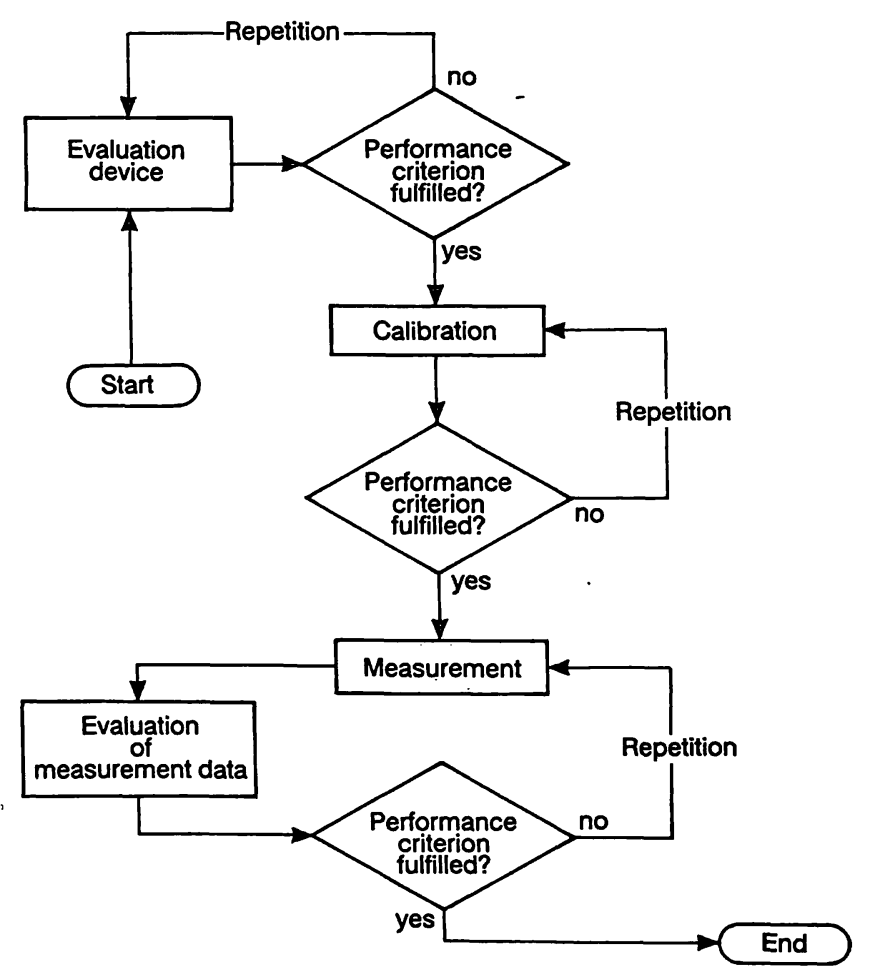

Fig. 7. Performance criteria in reference procedure. the calibration. Table 5 shows some examples of such criteria. Finally, suitable control and test methods for the measuring operation in the narrower sense must be included in the protocol. It should be checked whether the measurement data obtained give a valid set of readings before the results are calculated. Some examples of this criterion are shown in table 6.

Tab. 5. Performance criteria of calibration.

Example: Reference method for potassium (NBS) (41)

Comparison of standard stock solutions
difference $\leqq 0.5 \%$

"Standard deviation of fit" $\leqq 0.075 \mathrm{mmol} / 1$

$\hat{y}=a+b \cdot x_{i}$ $y_{i}-\hat{y}=d_{i}$

$$
s_{\mathrm{nit}}^{2}=\sum_{i=1}^{n} d_{i}^{2} /(n-2)
$$

Example: Reference method for calcium (BCR) (2)

"Precision index" $\mathrm{s} / \mathrm{b} \leqq 0.020 \mathrm{mmol} / \mathrm{l}$

Precision index $=\frac{\text { residual standard deviation } \mathrm{s}}{\text { mean slope } \mathrm{b}}$

Tab. 6. Performance criteria of measurement.

Example: Reference method for potassium (NBS) (41)

"Valid set of readings"

Standard deviation of all measuring results $<0.063 \mathrm{mmol} / \mathrm{l}$

Deviation from previous result
for sample and standards
$\leqq 2 \%$

Quality control

Deviation from "true value"
for certified reference material
$<0.065 \mathrm{mmol} / \mathrm{l}$


Reference methods are preferably used in clinical chemistry to investigate calibration and control materials. For reasons of stability, these materials are usually present in the lyophilized individual samples. This can result in systematic errors, for example due to filling inaccuracies ("vial-to-vial variability") which can be detected by a specific test design. The reconstitution of these samples also causes an error. Where appropriate, the analysis result should be related to the dry mass and not to the reconstituted volume.

In addition to the value obtained for the quantity sought, the final result of a reference method analysis should contain an indication of the uncertainty. Due to the aforementioned relationship between bias and imprecision, it does not suffice merely to indicate a standard deviation for the result. For this purpose some suggestions have been made by Eisenhart (52) (see also $K u(53)$ ):

The final result should be qualified by the following statements:

1. error limits of the systematic error (bias)

2. standard error, including degrees of freedom.

This may be illustrated by the following example:

Reference method sodium (NBS), control material no. 558

result: sodium $139.27 \mathrm{mmol} / 1$

bias determined with SRM 909 (NBS): $-0.05 \ldots+0.17$

$\mathrm{mmol} / \mathrm{l}$

standard error from 20 determinations: $0.32 \mathrm{mmol} / \mathrm{l}$

\section{Some Remarks on the Use of Reference Methods in a Reference System}

We have based this discussion on the necessity of a reference system for improving the comparability of clinical chemical routine tests. Figure 8 illustrates the function of the reference methods in such a reference system. In routine analyses, calibrators and control materials must be used, which are analysed by a reference method. The reference method itself is calibrated by ultrapure CRM's and controlled by matrixed CRM's. Both are - if possible - analysed by means of a definitive method. Of great importance is the investigation of the control materials used for external and internal quality control by means of reference methods on a regular basis. The Second Atlanta Conference in 1977 (7) as well as Tietz (10), Stamm (11, 54), Leijnse (30) and others have championed this principle emphatically. In addition, reference methods are necessary for analysing matrixcontaining calibrators as required today in many analysis systems for calibration. Finally, reference methods should be increasingly used to test new routine methods.

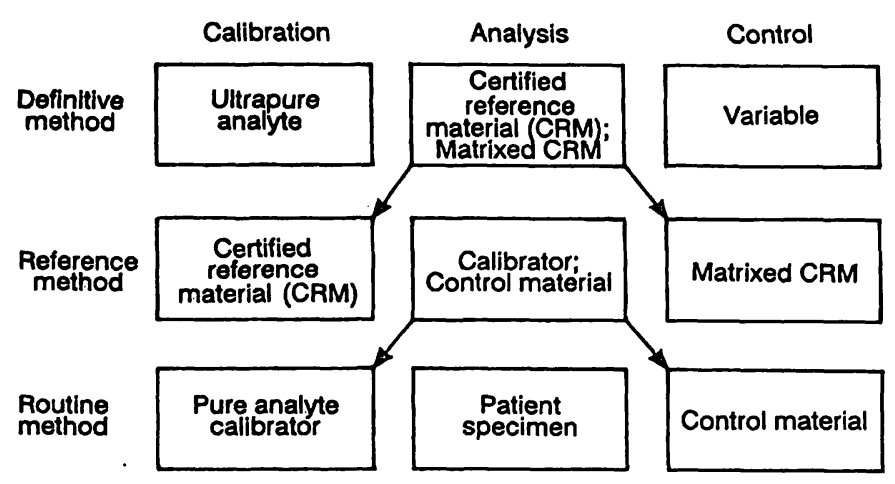

Fig. 8. Reference system in clinical chemistry.

The outlined function of reference methods within the quality control make it essential to develop a method for official approval of reference methods. In recent years a relative large number of methods in the area of clinical chemistry have been described as "definitive methods" or "reference methods". Not all these methods meet the requirements made (see, for example, the report by Eldjarn \& Broughton (55)). It would be very desirable if as soon as possible corresponding scientific evaluation procedures were developed for "candidate methods" and implemented by suitable organizations for arriving at internationally accepted definitive or reference methods. This could be done on an international, supranational or national level. A recommendation for an European standard on "Reference Measurement Procedure. Elements, Structure, Format" is at present being worked out at CEN TC 140, Working Group 4 (56). Table 7 summarizes some essentials for the acknowledgement of reference methods.

Tab. 7. Essential requirements in the approval of reference methods (proposal).

1. Analytical principle well known for its specificity and accuracy.

2. Definition of performance criteria for the procedure control.

3. Detailed description of the procedure available.

4. Carefully documented evaluation of accuracy and interferences by means of

- comparison with definitive method (if available)

- certified reference materials

- interference studies

5. Carefully designed transferability study including at least 3 laboratories.

6. Goals for acceptability as reference method (depending on medical needs)

\begin{tabular}{lll} 
& $\begin{array}{l}\text { Within } \\
\text { laboratory }\end{array}$ & $\begin{array}{l}\text { Between } \\
\text { laboratories }\end{array}$ \\
\cline { 2 - 3 } $\begin{array}{l}\text { Bias } \\
\text { Imprecision }\end{array}$ & $\begin{array}{l} \pm \ldots 3 \% \\
0.5 \ldots 1.5 \% \text { (rel. SD) } \\
\text { over the medically important analytical } \\
\text { range. }\end{array}$ & $\begin{array}{l} \pm \ldots 3 \% \\
\text { la }\end{array}$ \\
\hline
\end{tabular}




\section{Conclusion}

In our consideration of reference methods, emphasis has been placed on the urgent problem of the accuracy of clinical chemical analyses and the metrological aspects resulting therefrom. For a long time, in the development of clinical chemical routine methods and analysis systems, far greater attention was paid to precision than to accuracy. It is only with the development of reference methods and reference materials that an objective basis has been created for testing the accuracy of routine methods. We should make use of this possibility. Improvement of the accuracy is difficult and tiresome; however, it is not without reason that the English term "accuracy" derives from the Latin verb accurare which means "do something with special care" (The German térm "Richtigkeit", like the English term "correctness" is more neutral. Both these words are related to the Latin "rectus" (straight)).

\section{References}

1. Meinke, W. W. (1971) Standard reference materials for clinical measurements. Anal. Chem. 43, 28A-47A.

2. Cali, J. P., Mandel, J., Moore, L. \& Young, D. S. (1972) A Reference Method for the Determination of Calcium in Serum [NBS Special Publication 260-36]. U.S. Government Printing Office, Washington D.C.

3. Cali, J. P. (1974) A systematic approach to accuracy in clinical chemistry. Medical Instrumentation [Arlington] 8, $17-21$.

4. Cali, J. P., Mears, T. W., Michaelis, R. E., Reed, W. P., Seward, R. W., Stanley, C. L., Yolken, H. T. \& Ku, H. H. (1975) The Role of Standard Reference Materials in Measurement Systems [NBS Monogr. 148]. U. S. Government Printing Office, Washington D.C.

5. Cali, J. P. (1976) Rationale for reference methods in clinical chemistry. Pure and Applied Chemistry 45, 63-68.

6. U.S. Department of Health, Education, and Welfare (1974) Proceedings: International Conference on Standardization of Diagnostic Materials. June 5-8, 1973, Atlanta, $\mathrm{Ga}$.

7. Boutwell, J. H. (Editor) (1978) A National Understanding for the Development of Reference Materials and Methods for Clinical Chemistry. Proceedings of a Conference. American Association for Clinical Chemistry, Washington, D. C.

8. Büttner, H. (1976) The International Federation of Clinical Chemistry (IFCC) and reference methods. Pure and Applied Chemistry 45, 69-73.

9. Rinsler, M. G. \& Mitchell, F. L. (1974) Reference materials and methods in clinical chemistry. Z. Klin. Chem. Klin. Biochem. 12, 588-574.

10. Tietz, N. W. (1979) A model for a comprehensive measurement system in clinical chemistry. Clin. Chem. 25, $833-839$.

11. Stamm, D. (1982) A new concept for quality control of clinical laboratory investigations in the light of clinical requirements and based on reference method values. $J$. Clin. Chem. Clin. Biochem. 20, 817-824.

12. Bundesärztekammer (1988) Richtlinien der Bundesärztekammer zur Qualitätssicherung in medizinischen Laboratorien. Deutsches Ärzteblatt 85, A699-A712.

13. Uriano, G. A. \& Cali, J. P. (1977) Role of reference materials and reference methods in the measurement process. In: Validation of the Measurement Process (ACS Symposium Series 63] (De Voe, J. R., ed.) American Chemical Society, Washington, pp. $140-161$.

14. Büttner, J. (1988) Fundamental aspects of measurement in Clinical Chemistry. Fourth Asian-Pacific Congress of Clinical Biochemistry. Proceedings (Lin, H. J., Swaminathan, R. \& Robertshaw, A. R., eds.) Hongkong, GardinerCaldwell Communications Ltd., pp. 403-409.

15. Dybkaer, R. (1978) IFCC Approved recommendation (1978) Quantities and units in Clinical Chemistry. J. Clin. Chem. Clin. Biochem. 17, 807-821, and

Dybkaer, R. (1979) IFCC Approved Recommendation (1978) List of quantities in Clinical Chemistry. J. Clin. Chem. Clin. Biochem. 17, 822-835.

16. Dorsey, N. E. (1944) The velocity of light. Transaction of the American Philosophical Society 34,1-110.

17. DIN Deutsçhes Institut für Normung e. V. (1984) Internationales Wörterbuch der Metrologie - International Vocabulary of Basic and General Terms in Metrology. Beuth Verlag GmbH, Berlin, Köln.

18. Eisenhart, C. (1963) Realistic evaluation of precision and accuracy of instrument calibration systems. J. Research National Bureau of Standards 67C, 161-187.

19. Mandel, J. (1964) The Statistical Analysis of Experimental Data. Interscience Publishers, New York, London, Sydney.

20. Ku, H. H. (Editor) (1969) Precision Measurement and Calibration - Statistical Concepts and Procedures [NBS Special Publication 300, Vol. 1]. U.. S. Government Printing Office, Washington D.C.

21. Currie, L. A. (1978) Sources of error and the approach to accuracy in analytical chemistry. In: Treatise on Analytical Chemistry (Kolthoff, I. M. \& Elving, P. J., eds.) 2nd Edition, J. Wiley \& Sons, New York. Part I, Vol. 1, pp. 95-242.

22. Shewhart, W. A. (1931) Economic Control of Quality of Manufactured Product. D. Van Nostrand Co., Inc. Toronto, London, New York.

23. o.c. (22), p. 12.

24. Büttner, J., Borth, R., Boutwell, J. H., Broughton, P. M. \& Bowyer, R. C. (1979) IFCC. Approved recommendation (1978) on quality control in clinical chemistry. Part 1 : General principles and terminology. Clin. Chim. Acta 98, F129-F143, and J. Clin. Chem. Clin. Biochem. 18, $69-77$.

25. 1.c. (16), p. 4.

26. Cali, J. P. \& Reed, W. P. (1976) The role of the National Bureau of Standards. Standard Reference Materials in Accurate Trace Analysis: In: Accuracy in Trace Analysis: Sampling, Sample Handling, and Analysis (La Fleur, P. D., ed.) [NBS Special Publication 422]. U.S. Governmènt Printing Office, Washington D. C. Vol. 1, pp. 41-63.

27. Neill, D. W. \& Doggart, J. R. (1976) Letter to the editor: When is a reference method a reference method? Clin. Chem. 22, 285.

28. Brown, S., Büttner, J., Mitchell, F. L., Rubin, M. \& Cooper, G. R. (1976) Letter to the editor: When is a reference method a reference method? Clin. Chem. 22, $285-286$

29. Cali, P., Schaffer, R. \& Mitchell, F. L. (1977) Suggested modification of the definition for definitive method. Clin. Chem. 23, 1943-1944.

30. Leijnse, B. (1982) Definitive methods - reference methods (absolute methods?): their important impact on clinical chemistry. Ann. Clin. Biochem. 19, 289-294. 
31. o.c. (7), p. 304.

32. Uriano, G. A. \& Gravatt, C. C. (1977) The role of reference materials and reference methods in chemical analysis. CRC Critical Reviews in Analytical Chemistry 6, 361 411.

33. De Leenheer, A. P., Lefevere, M. F., Lambert, W. E. \& Colinet, E. S. (1985) Isotope dilution mass spectrometry in clinical chemistry. Adv. Clin. Chem. 24, 111-161.

34. Siekmann, L. (1989) Reference methods. In: Mass Spectrometry (Clinical Biochemistry, 1) (Lawson, A. M., ed.) W. de Gruyter Verlag, Berlin, New York, pp. 644-681.

35. Büttner, J. (1986) Reference methods vs. standardized methods. [Vortrag Treffen Europäischer Enzymologen, 13./14. 2. 1986, Frankfurt]. Deutsche Gesellschaft für Klinische Chemie - Mitteilungen 17, 338-341.

36. Feldmann, U., Schneider, B., Klinkers, H. \& Haeckel, R. (1981) A multivariate approach for the biometric comparison of analytical methods in clinical chemistry. J. Clin. Chem. Clin. Biochem. 19, 121-137.

37. Carey, R. N., Wold, S. \& Westgard, J. O. (1975) Principal component analysis: An alternative to 'referee' methods in method comparison studies. Anal. Chem. 47, 18241829.

38. o.c. (19).

39. $\mathrm{Ku}, \mathrm{H}$. H. (1966) Notes on the use of propagation of error formulas. J. Research National Bureau of Standards $70 C$, (4), 263-273.

40. Anlage zur Eichordnung vom 12. August 1988, Anlage 12 , Volumenmeßgeräte für Laboratoriumsgeräte. Bundesgesetzblatt, Teil I Nr. 43 v. 26. 8. 1988, Anlagen-Band.

41. Velapoldi, R. A., Paule, R. C., Schaffer, R., Mandel, J., Machlan, I. A. \& Gramlich, J. W. (1979) Standard reference materials: a reference method for the determination of potassium in serum [NBS Special Publication 260263]. U. S. Government Printing Office, Washington, D. C.

42. Yap, W. T., Schaffer, R., Hertz, H. S., White, V. E. \& Welch, M. J. (1983) On the difference between using linear and non-linear models in bracketing procedures in isotope dilution mass spectrometry. Biomedical Mass Spectrometry $10,262-264$.

43. Schwartz, L. M: (1977) Nonlinear calibration. Anal. Chem. 49, 2062-2068.

44. Kaiser, H. (1972) Zur Definition von Selektivität, Spezifität und Empfindlichkeit von Analysenverfahren. Fresenius' Z. Anal. Chem. 260, 252-260.

45. Kaiser, H. (1973) Grundlagen zur Beurteilung von Analysenverfahren. In: Methodicum Chimicum (Korte, F., Hrsg.) Georg Thieme Verlag, Academic Press Stuttgart, New York, London, Band 1, Analytik, Teil 1, pp. 1-20.

46. Kroll, M. H., Ruddel, M., Blank, D. W. \& Elin, R. J. (1987) A model for assessing interference. Clin. Chem. 33, $1121-1123$.

47. Saxberg, B. E. H. \& Kowalski, B. R. (1979) Generalized standard addition method. Anal. Chem. 51, 1031-1038.

48. Sharaf, M. A., Illman, D. L. \& Kowalski, B. R. (1986) Chemometrics [Chemical Analysis, Vol. 82]. John Wiley \& Sons, New York.

49. Brown, S. S., Healy, M. J. R. \& Kearns, M. (1981) Report on the inter-laboratory trial of the reference method for the determination of total calcium in serum. Part I. J. Clin. Chem. Clin. Biochem. 19, 395-412, and

Brown, S. S., Healy, M. J. R. \& Kearns, M. (1981) Report on the inter-laboratory trial of the reference method for the determination of total calcium in serum. Part II. J. Clin. Chem. Clin. Biochem. 19, 413-426.

50. Schaffer, R., Mandel, J., Sun, J., Cohen, A., Hertz, H. S. \& Neese, J. W. (1982) Standard Reference Materials: Evaluation by an ID/MS Method of the AACC Reference Method for Serum Glucose. INBS Special Publication $260-80]$. U. S. Government Printing Office, Washington, D.C.

51. Cooper, G. R., Smith, S. J., Duncan, I. W., Mather, A., Fellows, W. D., Foley, T., Frantz, I. D. Jr., Gill, J. B.,
Grooms, T. A., Hymie, I., Laessig, R., LoBasso, F. A., Martin, J., Naito, H., Newman, H. A., Sideman, L., Turner, J. H. \& Williams, D. (1986) Interlaboratory testing of the transferability of a candidate reference method for total cholesterol in serum. Clin. Chem. 32, $921-929$.

52. Eisenhart, C. (1968) Expression of the uncertainties of final results. Clear statements of the uncertainties of reported values are needed for their critical evaluation. Science $160,1201-1204$.

53. $\mathrm{Ku}, \mathrm{H}$. H. (1968) Expressions of imprecision, systematic error, and uncertainty associated with a reported value. Measurements and Data 2, 72-77.

54. Stamm, D. (1986) Erfahrungen mit Referenzmethoden. Fresenius' Z. Anal. Chem. 324, 204-205.

55. Eldjarn, L. \& Broughton, P. M. (1985) Methods of assigning accurate values to reference serum. Part 2 . The use of definitive methods, reference laboratories, transferred values and consensus values. Ann. Clin. Biochem. $22,635-649$.

56. Comité Européen de Normalisation (CEN)/Technical Committee 140 (In-vitro diagnostics), Working Group 4 (1991) Reference Measurement Procedure. Elements, Structure, Format (Draft). Document N22E

57. Moore, L. J. \& Machlan, L. A. (1972) High-accuracy determination of calcium in blood serum by isotope dilution mass spectrometry. Anal. Chem. 44, $2291-2296$.

58. Gramlich, J. W., Machlan, L. A., Brletic, K. A. \& Kelly, W. R. (1982) Thermal-ionization isotope-dilution mass spectrometry as a definitive method for determination of potassium in serum. Clin. Chem. 28, 1309-1313.

59. Siekmann, L., Hüskes, K. P. \& Breuer, H. (1976) Determination of cholesterol in serum using mass fragmentography - a reference method in clinical chemistry. Fresenius' Z. Anal. Chem. 279, 145-146.

60. Gambert, P., Lallemant, A., Archambault, A., Maume, B F. \& Padieu, P. (1979) Assessment of serum cholesterol by two methods: Gas-liquid chromatography on a capillary column and chemical ionization-mass fragmentography with isotopic dilution of $\left(3,4-{ }^{13} \mathrm{C}\right)$ cholesterol as internal standard. J. Chromatography 162, 1-6.

61. Cohen, A., Hertz, H. S., Mandel, J., Paule, R. C., Schaffer R., Sniegoski, L. T., Sun, T., Welch, M. J. \& White, V. E. (1980) Total serum cholesterol by isotope dilution/mass spectrometry: A candidate definitive method. Clin. Chem. 26, 854-860.

62. Freudenthal, J., Derks, H. J. G. M., Gramberg, L. G., ten Hove, G. J. \& Klaassen, R. (1981) Isotope dilution mass spectrometry of cholesterol in serum. Biomedical Mass Spectrometry 8, 5-9.

63. Pelletier, O., Wright, L. A. \& Breckenridge, W. C. (1987) Isoptope dilution/Mass spectrometry of serum cholesterol with $\left[3,4-^{13} \mathrm{C}\right]$ cholesterol: Proposed definitive method. Clin. Chem. 33, 1403-1411.

64. Ellerbe, P., Meisleman, S., Sniegoski, L. T., Welch, M. J. \& White, E. (1989) Determination of serum cholesterol by a modification of the isotope dilution mass spectrometric definitive method. Anal. Chem. 61, 1718-1723.

65. White, V. E., Welch, J., Sun, T., Sniegoski, L. T., Schaffer, R., Hertz, H. S. \& Cohen, A. (1982) The accurate determination of serum glucose by isotope dilution mass spectrometry - two methods. Biomedical Mass Spectrometry 9, 395-405.

66. Pelletier, O. \& Arratoon, C. (1987) Precision of glucose measurements in control sera by isotope dilution/mass spectrometry: Proposed definitive method compared with a reference method. Clin. Chim. 33, 1397-1402.

67. Schumann, G. \& Büttner, J. (1988) Determination of glucose in reference materials by isotope dilution-mass spectrometry. Fresenius Z. Anal. Chem. 330, 424-425.

68. Siekmann, L. (1985) Determination of crcatinine in human serum by isotope dilution-mass spectrometry. Definitive methods in clinical chemistry, IV. J. Clin. Chem. Clin. Biochem. 23, 137-144. 
69. Welch, M. J., Cohen, A., Hertz, H. S., Kwokei, J. N., Schaffer, R., Van der Lijn, P. \& White, V. E. (1986) Determination of serum creatinine by isotope dilution mass spectrometry as a candidate definitive method. Anal. Chem. 58, 1681-1685.

70. Welch. M. J.. Cohen, A., Hertz, H. S., Ruegg, F. C., Schaffer, R., Sniegoski, L. T. \& White, W. V. (1984) Determination of serum urea by isotope dilution mass spectrometry as a candidate definitive method. Anal. Chem. 56, 713-719.

71. Siekmann, L. (1985) Definitive methods in clinical chemistry. III. Determination of uric acid in human serum by isotope dilution-mass spectrometry. J. Clin. Chem. Clin. Biochem. 23, 129-135.

72. Siekmann, L. \& Röhle, G. (1986) Reference methods for the deternination of steroids and uric acid by the use of isotope dilution-mass spectrometry. Fresenius $Z$. Anal. Chem. 324, 208-209.

73. Kock. R.. Delvoux, B., Tillmanns, U. \& Greiling, H. (1989) A candidate reference method for the determination of uric acid in serum based on high performance liquid chromatography, compared with an isotope dilution-gas chromatography-mass spectrometer method. J. Clin. Chem. Clin. Biochem. 27, 157-162.

74. Siekmann, L.. Schönfelder, A. \& Siekmann, A. (1986) Isotope dilutions-mass spectrometry of total glycerol in human serum - a reference method in clinical chemistry. Fresenius Z. Anal. Chem. 324, 280-281.

75. Koolstra, W., Wolthers, B. G., Hayer, M. \& Elzinga, H. (1987) Development of a reference method for determining urinary oxalate by means of isotope dilution-mass spectrometry (ID-MS) and its usefulness in testing existing assays for urinary oxalate. Clin. Chim. Acta 170, 227235.

76. Siekmann, L. (1978) Isotope dilution-mass spectrometry of oestriol and oestradiol-17-beta: an approach to definitive methods. Fresenius $Z$. Anal. Chem. 280, 122-123.

77. Siekmann, L. (1978) Isotope dilution-mass spectrometry of steroid hormones. A definitive method in clinical chemistry. In: Quantitative Mass Spectrometry in Life Sciences (de Leenheer, A. P., Roncuccu, R. R., van Peteghem, C., eds.) Vol. II, pp. 3-16. Elsevier Scientific Publishing Co., Amsterdam, Oxford, New York.

78. Siekmann, L. (1979) Determination of steroid hormones by the use of isotope dilution-mass spectrometry: A definitive method in clinical chemistry. J. Steroid Biochemistry $11,117-123$.

79. Siekmann, L. \& Breuer, H. (1982) Determination of cortisol in human plasma by isotope dilution-mass spectrometry. Definitive methods in clinical chemistry I. J. Clin. Chem. Clin. Biochem. 20,883-892.

80. Jonckheere, J. A. \& De Leenheer, A. P. (1983) Candidate definitive method for the determination of cortisol in human serum. Biomedical Mass Spectrometry 10, 197202.

81. Siekmann, L. (1984) Determination of oestradiol-17 beta in human serum by isotope dilution-mass spectrometry. Definitive methods in clinical chemistry II. J. Clin. Chem. Clin. Biochem. 22, 551-557.

82. Patterson, D. G., Patterson, M. B., Culbreth, P. H., Fast, D. M., Holler, J. S., Sampson, E. J. \& Bayse, D. D. (1984) Determination of steroid hormones in a human-serum reference material by isotope dilution-mass spectrometry: a candidate definitive method for cortisol. Clin. Chem. $30,619-626$.

83. Moeller, B., Balk, O. \& Bjoerkhem, I. (1983) Isotope dilution-mass spectrometry of thyroxin proposed as a reference method. Clin. Chem. 29, 2106-2110.

84. Siekmann, L. (1987) Measurement of thyroxine in human serum by isotope dilution mass spectrometry. Definitive methods in clinical chemistry V. Biomed. Environ. Mass Spectrometry $14,683-688$.
85. Gaskell, S. J. (1980) Gas chromatography/high-resolution mass spectrometry as a reference method for clomipramine determination. Postgrad. Med. J. 56, Suppl. 1, 90-93.

86. IFCC Maas, A. H. J., Weisberg, H. F., Zijlstra, W. G., Durst, R. A. \& Siggaard-Andersen, O. (1983) Reference method for $\mathrm{pH}$ measurement in blood. Clin. Chim. Acta 134, 371F-378F and J. Clin. Chem. Clin. Biochem. 21, $313-321$.

87. Maas, A. H. J., Weisberg, H. F., Burnett, R. W., MüllerPlathe, O., Wimberly, P. D., Zijlstra, W. G., Durst, R. A. \& Siggaard-Andersen, O. (1987) International Federation of Clinical Chemistry. Reference method (1986) for $\mathrm{pH}$ measurement in blood. J. Clin. Chem. Clin. Biochem. 25, 281-289 and Clin. Chim. Acta 165, 97-109.

88. Velapoldi, R. A., Paule, R. C., Schaffer, R., Mandel, J., Murphy, T. J. \& Gramlich, J. W. (1979) Standard reference materials: A reference method for the determination of chloride in serum. [NBS Special Publication 260-67]. U.S. Government Printing Office, Washington, D.C.

89. Velapoldi, R. A., Paule, R. C., Schaffer, R., Mandel, J. \& Moody, J. R. (1978) A Reference Method for the Determination of Sodium in Serum [NBS Special Publication $260-60]$. U.S. Government Printing Office, Washington, D. C.

90. Schaffer, R., Velapoldi, R. A., Paule, R. C., Mandel, J., Bowers, G. N. Jr., Copeland, B. E., Rodgerson, D. O. \& White, J. C. (1981) A multilaboratory-evaluated reference method for the determination of serum sodium. Clin. Chem. 27, 1824-1828.

91. Cali, J. P., Bowers jr., G. N. \& Young, D. S. (1973) A reference method for the determination of total calcium in serum. Clin. Chem. 19, 1208-1213.

92. Külpmann, W. R., Ruschke, D., Büttner, J. \& Paschen, K. (1989) A candidate reference method for the determination of magnesium in serum. J. Clin. Chem. Clin. Biochem. 27, 33-39.

93. Velapoldi, R. A., Paule, R. C., Schaffer, R., Mandel, J., Machlan, L. A., Garner, E. L. \& Rains, T. C. (1980) Standard reference materials: A reference method for the determination of lithium in serum [NBS Special Publication 260-69]. U.S. Government Printing Office Washington, D. C.

94. Brown, S. S., Nomoto, S., Stoeppler, M. \& Sundermann, F. W. (1981) IUPAC reference method for analysis of nickel in serum and urine by electrothermal atomic absorption spectrometry. Clin. Biochem. (Ottawa) 14, 295299.

95. Van Kampen, E. J. \& Zijlstra, W. G. (1965) Determination of hemoglobin and its derivatives. Adv. Clin. Chem. 8, $141-187$.

96. Recommendations for reference method for haemoglobinometry in human blood (ICSH standard 1986) and specifications for international haemiglobincyanide reference preparation (3rd edition). International Standard (1987) Clin. Lab. Haematol. 9, 73-79.

97. Doumas, B. T., Kwok-Cheung, P. P., Perry, B. W., Jendrzejczak, B., McComb, R. B., Schaffer, R. \& Hause, L. L. (1985) Candidate reference method for determination of total bilirubin in serum: development and validation. Clin. Chem. 31, 1779-1789.

98. Abell, L. L., Levy, B. B., Brodie, B. \& Kendall, F. E. (1952) A simplified method for the estimation of total cholesterol in serum and demonstration of its specifity. J. Biol. Chem. 195, 357-366.

99. Franzini, C. \& Besozzi, M. (1985) Proposed reference method for serum cholesterol assay. G. Ital. Chim. Clin. $10,251-256$.

100. Doumas, B. T., Bayse, D. D., Carter, R. J., Peters, T. Jr. \& Schaffer, R. (1981) A candidate reference method for determination of total protein in serum. I. Development and validation. Clin. Chem. 27, 1642-1650. 
101. Sampson, E. J., Baird, M. A., Burtis, C. A., Smith, E. M., Witte, D. L. \& Bayse, D. D. (1980) A coupled-enzyme equilibrium method for measuring urea in serum: optimization and evaluation of the AACC study group on urea candidate reference method. Clin. Chem. 26, 816-826.

102. Duncan, P. H., Gochman, N., Cooper, T., Smith, E. \& Bayse, D. (1982) A candidate reference method for uric acid in serum. I. Optimization and evaluation. Clin. Chem. $28,284-290$.

103. Neese, J. W., Duncan, P., Bayse, D., Robinson, M., Cooper, T. \& Stewart, C. (1976) Development and Evaluation of a Hexokinase/Glucose-6-Phosphate Dehydrogenase Procedure for Use as a National Glucose Reference Method [HEW Publication No. (CDC) 77-8330]. U.S. Dept. of Health, Education and Welfare, CDC, Atlanta, Ga.

104. Derks, H. J., van Heiningen, A. \& Koedam, H. C. (1985) Gas-chromatographic determination of cholesterol in serum: candidate reference method. Clin. Chem. 31, 691694.

105. Hartmann, L., Doree, G. \& Ambert, J. P. (1983) Gasliquid chromatography reference method for the assay of urinary creatinine. J. Chromatography 273, 235-243.

106. Juergens, U., May, T., Hillenkoetter, K. \& Rambeck, B. (1984) Systematic comparison of three basic methods of sample pretreatment for high-performance liquid chromatographic analysis of antiepileptic drugs; using gas chromatography as a reference method. Therapeutic Drug Monitoring 6, 334-343.
107. Ingebretsen, O. C., Borgen, J. \& Farstad, M. (1982) Highperformance liquid chromatography as a reference method for the determination of uric acid in human serum. XI International Congress of Clinical Chemistry (Kaiser, E., Gabl, F., Müller, M. M. \& Bayer, M., eds.) Walter de Gruyter, Berlin, New York, 1981, pp. 983-987.

108. Brechbuehler, T. \& Holinger, B. (1984) HPLC as a reference method for determination of uric acid. Bulletin Schweiz. Ges. Klin. Chem. 25, 143-148.

109. Schumann, G. \& Büttner, J. (1986) A candidate reference method for creatinine with HPLC. Fresenius' Z. Anal. Chem. 324, 278-279.

110. Reh, E. \& Jork, H. (1987) Determination of digoxin in human serum. Comparison of some immunological assays with an HPLC candidate reference method. Fresenius' $Z$. Anal. Chem. 327, 105-110.

111. Koolstra, W., Wolthers, B. G., Hayer, M. \& Rutgers, H. M. (1987) An improved high performance liquid chromatographic method for determining urinary oxalate making use of an ID-MS reference method. Clin. Chim. Acta $170,237-243$.

112. Schumann, G. \& Büttner, J. (1989) Highly accurate determinations of orthophosphate using high performance ion chromatography, proposed as a reference method (Abstract). J. Clin. Chem. Clin. Biochem. 27, 766-767.

113. Lemmens, A. A., Reijenga, J. C., Everaerts, F. M., Janssen, R. T., Hulsman, J. A. \& Meijers, C. A. M. (1985) Isotachophoresis as a candidate reference method in analytical chemistry. Determination of sodium in serum. J. Chromatography 320, 193-197.

Prof. Dr. Dr. J. Büttner Institut für Klinische Chemie I Medizinische Hochschule Hannover Konstanty-Gutschow-Straße 8 W-3000 Hannover 61 Bundesrepublik Deutschland 
